\title{
Arte, Internet y la reinvención de la televisión: el caso TV Swansong.
}

\section{Art, Internet and the reinvention of televisión. The Swansong TV case.}

\author{
Toni Roig Telo \\ Universitat Oberta de Catalunya \\ aroigt@uoc.edu
}

Ingeniero de Telecomunicaciones (1992) y Licenciado en Comunicación Audiovisual (1998). Desde 1999 profesor de los Estudios de Ciencias de la Información y de la Comunicación en la UOC- donde coordina el Área de Proyectos y Producción Audiovisual- y Director del Programa de Comunicación Audiovisual de la UOC desde sus inicios.

\section{Resumen}

Las posibilidades abiertas por la digitalización e Internet han propiciado un proceso de profunda transformación en el sector audiovisual. Paralelamente aparecen iniciativas independientes interesadas en las ind posibilidades emergentes de los denominados new media. Desafiando los planteamientos tradicionales en los estudios sobre comunicación de masas, Internet ofrece nuevos horizontes de participación, televisión. El propósito de esta investigación es analizar Internet TV project, Swansong TV, which originated in las características de un proyecto independiente de the context of the British visual arts. My objective is to televisión en Internet, TV Swansong, nacido en el establish how television characteristics are being marco del videoarte británico, con el objetivo de redefined or reproduced in a new context, in a product establecer cómo se redefinen o reproducen las where live transmission, pre-recorded video, web and características de la televisión en un nuevo contexto, online communication are simultaneously integrated donde se interrelacionan directo, diferido, web o and fragmented. I will also try to analyse the inherent comunicación en línea, al mismo tiempo que se tensions between local and global issues, producers analizan las tensiones entre lo local $\mathrm{y}$ lo global, and audience as well as the trans-generic nature of productores y audiencia y el cruce de géneros reflejado some programmes. en algunos de sus programas.

Para lograr los objetivos planteados en este estudio de caso se ha adoptado un enfoque cualitativo, interview, textual analysis and participant observation. combinando la entrevista con el análisis textual y la observación participante.

Palabras clave: Televisión digital, Internet, Keywords: Digital television, Internet, webcasting, new webcasting, new media media 


\section{Introducción}

Este artículo resume la investigación llevada a cabo en 2002 acerca de una iniciativa pionera en la televisión a través de Internet, escogida como estudio de caso en el contexto del seminario de investigación sobre cibercultura integrado en el programa de Doctorado Interdisciplinario de la Sociedad de la Información y el Conocimiento de la UOCi. Se trata de TV Swansong "(www.swansong.tv), híbrido entre proyecto artístico, web y televisión de origen británico. TV Swansong efectuó una emisión en directo el mes de marzo de 2002, y ha tenido una cierta prolongación a través de su sitio web.

El tema de investigación elegido parte del problema social de la transformación sufrida por los medios de comunicación, y particularmente la televisión a la luz de Internet, desde una doble vertiente: por un lado la llamada convergencia de medios y por otro la redefinición del rol de productores en relación con la audiencia.

Los objetivos generales que me propuse en esta investigación son:

- Determinar las características que conforman una emisión televisiva ideada pensando expresamente en Internet como medio de difusión.

- Comprender de forma holística las diferentes fases del proyecto (conceptualización, planificación, transmisión y post-emisión) así como su adaptación a las limitaciones y posibilidades técnicas del medio.

- Analizar la recepción y los usos de un producto televisivo emitido por Internet y su relación con la llamada "convergencia de medios".

- Estudiar el papel de los productores de televisión a través de Internet y sus diferencias con el papel de los productores en la televisión convencional.

- Observar cómo se redefinen modelos y patrones televisivos (modos de representación, programación, sentido del directo, modelos de participación, géneros, etc.) en este tipo de productos.

- Valorar la viabilidad de un proyecto de televisión por Internet y su relevancia dentro de un proceso de democratización de la expresión videográfica individual y colectiva a través de nuevos canales de difusión.

Para el análisis del caso de estudio formulé los siguientes objetivos concretos:

- Comparar el contexto de producción de TVSS con el entorno de la televisión institucional.

- Identificar la función de sus productores y su relación con la audiencia.

- Determinar la interacción entre las dimensiones artísticas, tecnológicas y autoreflexivas de TVSS.

- Analizar sus potencialidades expresivas dentro del marco de los new media.

- Estudiar modelos de producción, participación y recepción de TVSS, así como su aplicación en otros contextos culturales. 


\section{La era de la incertidumbre: relevancia social y científica de la investigación}

Vivimos en un momento en que la televisión sigue siendo centro de innumerables debates acerca de su propiedad, sus contenidos, su función, su uso y su futuro, en definitiva, su identidad. Tras el "siglo de la televisión" (V. Amela, 2002), nos encontramos en un momento de enorme incertidumbre acerca de su futuro (ver Ellis, 2000 y Castells, 2001).

Especialmente en Europa se han vivido unos años de constantes cambios relacionados con el modelo (público / privado, estatal/ regional/ local), acceso (abierto / codificado), sistemas de transmisión (red hertziana, cable, satélite), servicios (interactividad incipiente), etc. Se dice que vivimos tiempos inciertos para la televisión y el boom de Internet no ha hecho más que disparar la especulación sobre la posibilidad de que en un futuro no muy lejano los medios que hoy vivimos por separado se fusionen bajo un dispositivo único como objetivo último del proceso denominado "convergencia de medios" (Pérez de Silva, 2001).

A pesar de la viabilidad técnica y de los insaciables intereses comerciales, la "llamada convergencia" no parece tener un futuro fácil. La mayor crítica que se efectúa hacia este utópico modelo, alegremente difundido por los denominados, según el calificativo de Michael Heim, "Net idealists" ${ }^{\text {,iii", }}$ (adaptándolo a la ocasión podríamos hablar ahora de "Media Idealists"), proviene de los diferentes usos que se da a los terminales informáticos y a los receptores de televisión, que conforman experiencias individuales y colectivas totalmente diferentes (Castells, 2001). Haciendo una simplificación, podemos utilizar como ejemplo la contraposición entre las narrativas completas que pueblan los medios audiovisuales tradicionales y las narrativas incompletas del mundo digital (Lunenfeld, 2001). Pero a pesar de los serios interrogantes planean alrededor de la convergencia de medios, no hay duda de que la televisión está sufriendo un importante proceso de transformación y de crisis de identidad a causa de la expansión de las posibilidades ofrecidas por las tecnologías digitales.

La mayor parte de los estudios sobre la televisión parten de la consideración de la televisión, y más concretamente, la emisión de televisión como integrada en una realidad corporativa, sea de nivel local, regional, estatal o global. Esta dimensión corporativa se da por supuesta incluso en los principales estudios culturales sobre la televisión. En el núcleo de los debates acerca de los medios de comunicación (violencia televisiva, propiedad de los medios de comunicación, concentración, influencia política, publicidad, regulación, etc.), encontramos siempre esta dimensión institucional de la televisión. TVSS rompe esta dinámica, abriendo nuevas posibilidades a la investigación de la experiencia televisiva colectiva.

\section{Internet como medio de difusión: presentación del problema social}

En el transcurso de una entrevista durante el rodaje de "Apocalypse now", en 1979, Francis Ford Coppola afirmaba que con la llegada de las cámaras de vídeo sería posible revelar a un joven genio de la imagen de la misma forma que un genio de la música podría mostrarse al mundo con sólo poder acceder a un instrumento. 
Resulta por lo menos comprometido afirmar que la utópica premonición de Coppola se ha hecho realidad (afortunadamente no hay composiciones musicales de piano que exijan presupuestos desorbitados ni equipos de cientos de personas) aunque sí es cierto que la generalización de las cámaras domésticas a lo largo de las dos anteriores décadas ha permitido una cierta democratización en las representaciones subjetivas de muchas sociedades tecnológicamente avanzadas. El vídeo doméstico generó un lenguaje propio, aunque siempre restringido no sólo por su limitada calidad de imagen, sino por la dificultad en completar el proceso de creación de un producto audiovisual ante la necesidad de un buen equipo de edición, sonorización y fundamentalmente un buen canal de difusión que permita poner en contacto a la obra con su público potencial. En este sentido la tecnología digital nos permite acceder a programas informáticos que nos ofrecen la posibilidad de editar e incluso transmitir vídeo y audio con una facilidad impensable hace una década. Pero si la evolución de las herramientas nos facilita el acceso a estas técnicas, el gran cambio se ha producido gracias a Internet, que se pone a nuestra disposición como medio de difusión a nuestro alcance, con un elevado grado de independencia. No es de extrañar que en este contexto muchas miradas se hayan dirigido hacia Internet como medio de transmisión de imágenes en movimiento, a pesar que los limitados anchos de banda dificultan la disponibilidad y la agilidad necesaria para la transmisión de imágenes de calidad.

La técnica más popular de transmisión de vídeo a través de Internet es el streaming, que consiste en un flujo de señal transmitido en directo a petición del usuario, sin que se requiera almacenar fichero de imagen. En estos últimos tiempos se ha popularizado la posibilidad de generar imágenes de vídeo desde una cámara digital para que puedan ser transmitidas con facilidad a través de la Red utilizando técnicas de streaming: esta tecnología recibe el nombre de webcasting iv (término heredado de "broadcasting"). El webcasting se ha venido utilizando en estos últimos años de forma experimental como evolución natural de la transmisión de imágenes fijas en tiempo real a través de las populares webcams, y ha tenido ya una repercusión importante en la representación del "self" en Internet, como indica Snyder (en Gauntlett, 2000). Y es que a pesar de sus limitaciones técnicas, el webcasting es la primera herramienta tecnológica que abre a un gran número de usuarios la posibilidad de publicar sus propias representaciones a una gran audiencia potencial (sin necesidad de esperar la oportunidad de difundir imágenes propias en un programa de vídeo doméstico en "prime time" veraniego). Sin embargo, aun son incipientes las iniciativas que hayan explorado las posibilidades del webcasting como medio de expresión artística, ni como medio de comunicación colectivo.

Más allá de las técnicas de animación pensadas para Internet (como la tecnología Flash), el vídeo se ha ido introduciendo gracias al streaming sobre todo con objetivos informativos (crónicas) y comerciales (trailers, vídeoclips, spots publicitarios y otros tipos de material promocional), y ha ido ganando presencia en sites vinculados a la televisión ${ }^{\vee}$. Sin embargo, la mayor parte de la producción no ha sido pensada específicamente para Internet como medio, o lo ha hecho utilizando las convenciones narrativas ajenas. Por este motivo, el vídeo volcado en Internet no puede conformar en sí mismo como un "nuevo medio" (Manovich, 2001, pp.45-48). Es por eso que para mi investigación resultaba esencial la selección de un caso en que el producto cultural se hubiera concebido y desarrollado pensado desde su origen en Internet como medio: como ser verá TVSS responde adecuadamente a los requisitos buscados. 


\section{Perspectiva metodológica}

A partir de las características del objeto de esta investigación, y habiéndome propuesto realizar un estudio de caso, utilicé para la misma un enfoque cualitativo. Las técnicas cualitativas utilizadas fueron la entrevista a las directoras y a algunos artistas implicados, el análisis textual del proyecto en su conjunto y la observación participante a través del simposio que se llevó a cabo tras la emisión. Para satisfacer la necesidad de una visión holística aproveché una variada serie de fuentes de obtención de datos, desde información textual y gráfica, publicaciones, entrevistas y documentación solicitada a los productores, archivos audiovisuales y participación activa en el proceso de reflexión de los productores y artistas.

El motivo que me llevó a escoger este enfoque es la adecuación de las técnicas cualitativas con las fuentes de datos requeridos para la investigación y la idoneidad de esta aproximación para atender a las diferentes sensibilidades que debemos poner en juego para evitar caer en determinadas trampas absolutistas, siguiendo las consideraciones de Silverman ${ }^{\mathrm{vi}}$, tratándose de una investigación centrada en el análisis cultural. En esta investigación tuve muy en cuenta la sensibilidad histórica, que nos permite efectuar una mirada crítica a la evolución de una determinada tecnología (en nuestro caso la televisión), la sensibilidad cultural (que hace hincapié en la experiencia como un proceso definido culturalmente) y también la sensibilidad contextual, esencial para entender el proceso de producción y recepción de un objeto cultural como TVSS.

La estructura de esta investigación pretende dar cuenta de la complejidad de TVSS, atendiendo a su condición de proyecto artístico, evento en directo, propuesta televisiva y producto en el que se funde la tecnología del webcasting, el arte digital, el diseño web, las interficies y la imagen digital, en un conjunto clasificable dentro de lo que denominamos new media siguiendo la definición propuesta por Manovich (Manovich, 2001, pp. 27-48). En este sentido veremos que TVSS nos ofrece múltiples posibilidades de comparar un producto híbrido que "simula" ser televisión con las características culturales de la propia televisión. Por otra parte, esta misma condición de producto híbrido por parte de TVSS nos resultará adecuado para hacer aflorar algunas de sus tensiones dialécticas ${ }^{\text {vii }}$, como las existentes entre los conceptos de acabado e inacabado, realidad y su representación, lo real y lo ideal, la experiencia del directo y del diferido y entre el acceso local y global (que también lo son al fin y al cabo de la televisión actual). Teniendo en cuenta la multiplicidad de puntos de vista necesarios para abordar de forma holística este proyecto, el marco teórico precisaba de modelos de reflexión sobre la propia televisión, para lo que me remití a la perspectiva de los estudios culturales, por su visión integradora de producto como "texto" con su recepción por parte de la audiencia (Fiske, Ellis, Nightingale, Livingstone, etc.). Para abordar la dimensión de TVSS como iniciativa en Internet contrasté la divergencia entre las visiones abiertamente ciberlibertarias hasta la teoría cultural de Internet (Swiss. McChesney) o la perspectiva sociológica (Castells). Finalmente, con el fin de estudiar un trabajo significativo dentro del entramado de TVSS, utilicé un modelo etnográfico basado en los modos de representación (Nichols, Ardévol), que nos permiten analizar modelos de colaboración, estilos de filmación y técnicas de montaje para ubicar las características participativas, críticas o reflexivas del objeto de estudio.

En base a todo lo expuesto anteriormente, y una vez acotado el caso de estudio, se propusieron las siguientes preguntas concretas de investigación: 
¿Cuál es la relación que se establece entre productores, producto y audiencia en un proyecto de televisión pensado para Internet como TVSS? ¿Podemos hablar de una redefinición estos términos?

¿Cuáles son las características y principales diferencias entre el contexto de producción de TVSS en relación con un proyecto de televisión convencional?

¿En qué sentido podemos hablar de convergencia de medios al analizar las principales constantes estructurales, estéticas y narrativas de TVSS?

\section{Los antecedentes de TVSS: Somewhere}

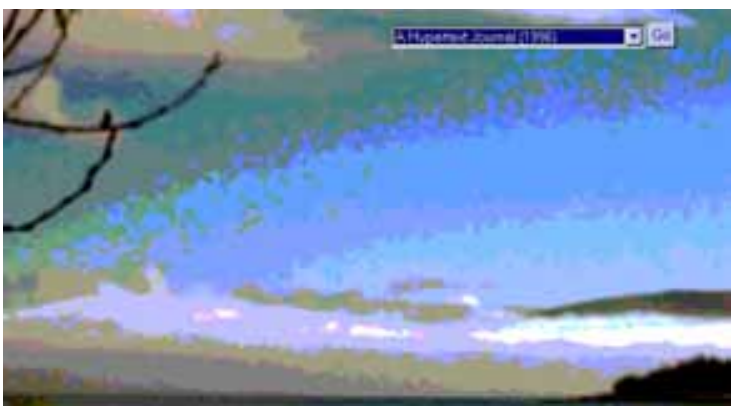

TVSS nace gracias al impulso de Karen Guthrie y Nina Pope, artistas británicas impulsoras de la iniciativa cultural en Internet Somewhere (www.somewhere.org.uk)

Desde 1995, Somewhere ha impulsado diversos proyectos utilizando en el ámbito de los new media, a través de vídeo, instalaciones, performances y retransmisiones (incluyendo webcasting, tal y como

han desarrollado especialmente para TVSS).

En el contexto del arte contemporáneo, la apropiación de las tecnologías digitales e Internet ha alterado muchas de sus convenciones (Boy et al., 1999 citados por Castells, 2001, p. 210). Entre ellas, tal y como se podrá observar a continuación, en los proyectos de Somewhere se asiste a un intento de disolución de los límites entre diferentes medios de expresión, así como entre autoría y audiencia (Castells, 2001). Las autoras ejemplifican este propósito al hablar de su proyecto Broadcast (1999):

.... close consideration of audience; questioning of the artists' role as sole 'author' within interactive and public arts practice; and the use of technology to re-examine cultural obsessions such as history and heritage and the articulation of contemporary notions of narrative.

(Pope y Guthrie, http://www.somewhere.org.uk/broadcast/index.htm)

Ciertamente, los proyectos auspiciados por Somewhere mantienen una clara continuidad de intereses y objetivos, principalmente explorar la intimidad de la experiencia del mundo mediada por la tecnología. A modo de ejemplo, las propias autoras utilizan la siguiente precisión poética hablando de uno de estos proyectos, The Hypertext Journal:

[This project].... reflects our interest in the potential of new media to re-enchant the past

(Pope y

Guthrie,

http://www.somewhere.org.uk/hypertext/journal/proj.info/index2.html) 
A continuación efectuaré una descripción de algunos de los más relevantes proyectos de Karen Guthrie y Nina Pope, deteniéndonos especialmente en los que prefiguran de forma más directa lo que terminará siendo TV Swansong. Si observamos la marcada coherencia entre ellos, no sorprende que TV Swansong, siendo un proyecto colectivo desarrollado en estrecha colaboración con otros artistas, mantenga las señas de identidad que ya se pueden intuir perfectamente a lo largo de la siguiente exposición:

\section{THE HYPERTEXT JOURNAL (1996)}

\section{(http://www.somewhere.org.uk/hypertext/journal/index.html)}

Los objetivos de The hypertext journal no pueden ser más alejados de una revista académica sobre el mundo del hipertexto. Se trata, en la línea de las revisitaciones históricas pasadas por el tamiz de las nuevas tecnologías que tanto atraen a sus autoras, de una interpretación contemporánea del viaje a través de Escocia que realizaron el Dr. Samuel Johnson y James Boswell en 1773. Las autoras se propusieron reproducir con la máxima

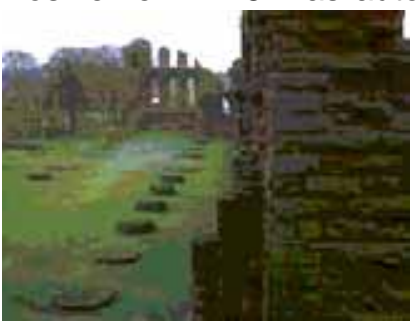
exactitud este mismo viaje utilizando Internet como medio de publicación de sus expectativas y vivencias. Durante el tiempo en que duró el viaje, Karen y Nina se dedicaron a actualizar diariamente su página web incorporando fotografía, texto, vídeo y sonido, a la vez que respondían todos los mensajes de correo electrónico o material adicional que les llegara del exterior. De esta forma, la memoria del viaje se formaría según las intenciones de sus autoras a través de un auténtico proceso de dialogo entre artistas y público. Existe un importante volumen de información adicional en la dirección web:

\section{http://www.somewhere.org.uk/hypertext/journal/proj.info/index2.html}

Con relación a TVSS supondrá un claro precedente del uso de la web como medio de comunicación y publicación de imagen y sonido. Por otra parte responde a su inquietud por situarse como pioneras en la exploración de las posibilidades expresivas de un medio, en este caso en el campo de las crónicas de viajes a través de Internet incorporando un diálogo entre productores/ viajeros y audiencia (lo que se conoce actualmente como "travelogue").

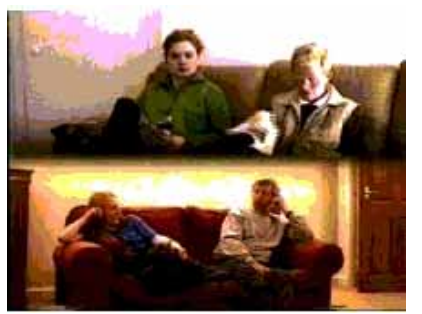

\section{HOMESPUN (1997-1998)}

\section{(http://www.somewhere.org.uk/homespun/index.htm)}

proyecto, Nina y Karen volvieron durante cinco días a sus hogares paternos, la campiña de Cambridgeshire y la costa de Largs respectivamente, creando diariamente una serie de fragmentos de video y documentos web. Cada día, las artistas creaban dos vídeos, uno de una escena doméstica y otra que mostraba el paisaje local. Luego ambos vídeos

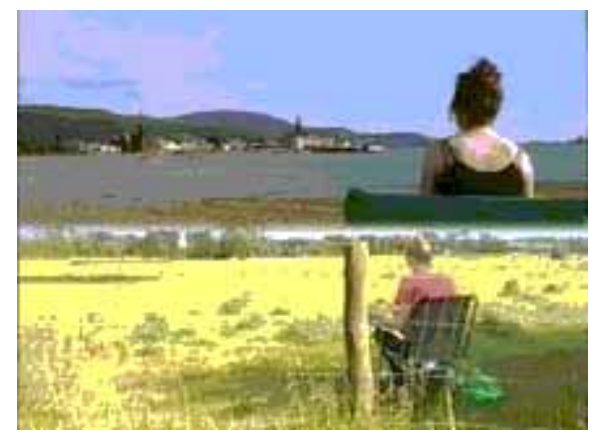


eran intercambiados, sincronizados y reproducidos en pantalla dividida en dos galerías de arte de forma simultánea. Toda la comunicación entre las artistas acerca de la planificación de las grabaciones del día siguiente podía seguirse también desde las propias galerías.

En definitiva, los objetivos de Homespun eran por un lado mostrar el contraste entre la nostalgia y la realidad del "hogar" revisitando tanto el paisaje exterior como la vida doméstica de los hogares familiares de las artistas, a la vez que intentaban dar la vuelta a lenguaje del vídeo doméstico familiar. Se trata de su primera incursión en el formato vídeo, utilizando ya en este estado tanto técnicas de retransmisión a través de streaming y evidenciando su interés tanto por la memoria de la infancia como por la búsqueda del arte lejos de los entornos urbanos (todos estos temas serán retomados a través de TVSS).

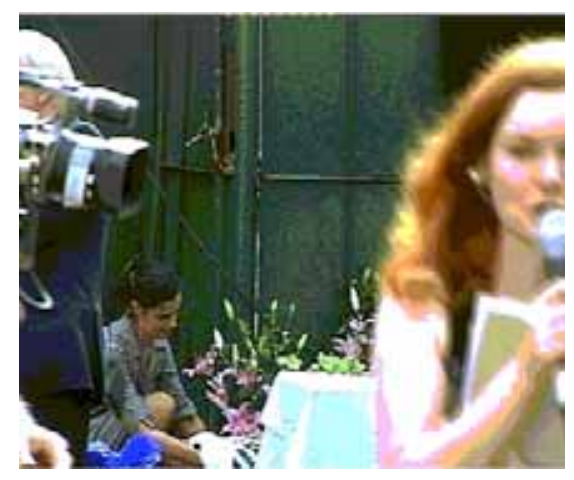

\section{BROADCAST (1999)}

(http://www.somewhere.org.uk/broadcast/index.htm)

Este proyecto, presentado en el Bankside Annual Event de 1999, se inspiró en los personajes del clásico "Los cuentos de Canterbury", en los que una serie de peregrinos, reunidos en la taberna "The Tabard" narraban cuentos relativos a su peregrinaje. Broadcast pretende reflexionar sobre el actual significado de "peregrinaje", el cuento como forma expresiva y el papel de la audiencia, mediante un acontecimiento en directo en el que, durante un día entero, unos "nuevos peregrinos" (seleccionados a

través de un cásting) idearon, grabaron y transmitieron 29 cuentos modernos exhibidos en el teatro del Borough Market, siguiendo una programación estricta. El proyecto dio lugar a una página web y un documental sobre el proyecto.

Como veremos más adelante, Broadcast anticipa muchos aspectos futuros de TVSS, como la necesidad de programación, la dualidad entre acontecimiento en directo y diferido y el uso del webcasting para la retransmisión de imágenes.

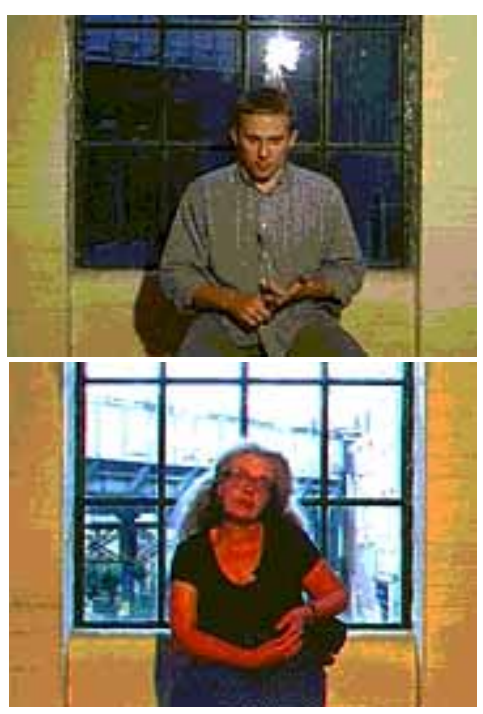

\section{GRIZEDALE PROJECTS (2000)}

(http://www.somewhere.org.uk/grizedale/index.htm)

Esta serie de proyectos fueron la culminación de una estancia de un curso académico en Cumbria, en el corazón de Inglaterra. Durante todo este tiempo, las artistas analizaron la conocida zona del Lake District desde el punto de vista de la cultura local, más que desde el más habitual del entorno natural. Fundamentalmente su trabajo de campo les llevó a explorar ciertas tradiciones e iconografías 
culturales locales a través del vídeo, el diseño gráfico y la web. Los proyectos de Grizedale suponen un refinamiento, especialmente técnico, de algunos de sus proyectos anteriores, mezclando vídeo y acontecimientos en directo, al lado de mantener su interés por el contraste entre la cultura local y la cultura urbana (utilizando una limousine para entrevistar a celebridades locales o reproduciendo a través de webcasting ciertas tradiciones), así como entre naturaleza y tecnología (diseñando una página web de contenido ecológico para un piloto

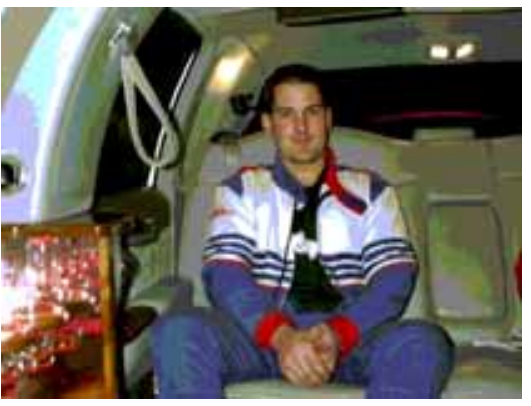
de rallies, http://www.grizedale.org/shuttle/).

\section{El salto hacia TVSS. Definición del proyecto.}

A través del recorrido que he efectuado a través de los proyectos de Somewhere, podemos deducir la aparición de un interés creciente por el vídeo, las transmisiones en directo, el contraste entre entorno natural y memoria y una creciente influencia de la estética de los medios de comunicación. Todos estos aspectos se hallan en el origen de TVSS. Según sus autoras, el salto definitivo de su obra anterior hacia TVSS viene motivado por un interés de realizar una obra colectiva, aproximándose al lenguaje de los medios de comunicación, planteándose dos preguntas muy generales sobre el mundo de la televisión:

- ¿Cómo la televisión articula y media la experiencia?

- ¿Cómo la televisión se sitúa en el centro de grandes cambios?

Estas preguntas determinan la condición de TVSS como intento de reflexión acerca de la propia televisión, a partir del reconocimiento de su valor cultural, aunque sin obviar una dimensión crítica en relación con esos "grandes cambios".

Así pues TVSS se presenta como proyecto colectivo, coordinado y gestionado por Pope y Guthrie, con la idea de reunir a artistas de diferentes ámbitos para crear ocho trabajos inéditos que reflejaran el significado actual de la televisión, a la vez que arrojaran una visión personal acerca de su pasado, presente y futuro (los objetivos del proyecto están accesibles en http://www.swansong.tv/back.htm). El reto era llevar a cabo una única retransmisión vía web partiendo de una escaleta perfectamente planificada: cada artista, desde una determinada localización transmitiría su trabajo vía webcast, de forma que fuera visible tanto para el público que quisiera acercarse a la localización escogida como a través de una conexión a Internet.

\section{La plataforma web: una ventana de oportunidad.}

¿Por qué difundir TVSS a través de la web? No se trata de una simple pregunta retórica, sino probablemente la primera y más importante decisión que tuvieron que tomar Pope y Guthrie. Como veremos más adelante, el relativamente holgado presupuesto de TVSS podría haber aconsejado su transformación en un producto de televisión de difusión convencional aunque fuera por vías alternativas. Como producto con voluntad de emisión única en directo, su difusión vía web planteaba una serie de problemas, por el acceso simultáneo, así como por la propia lógica de Internet, habituada a la independencia de tiempo y espacio. Por supuesto, la libertad temporal quedaría garantizada por los archivos de vídeo de la retransmisión, accesibles a otro tipo de audiencia remota, 
pero la voluntad de las autoras pasaba inexorablemente por la emisión en directo, por la retransmisión. Por otra parte, TVSS no es estrictamente un proyecto de televisión interactiva. ¿Cuáles son pues los motivos que empujaron a las artífices de TVSS a difundir su proyecto a través de Internet? Si tenemos en cuenta lo expuesto anteriormente, podemos aventurar algunas posibles respuestas:

Conocimiento del medio: como hemos visto anteriormente, el background de Nina Pope y Karen Guthrie se sitúa firmemente en las artes visuales y la exploración de las posibilidades de Internet. Se trata por tanto de un entorno en el que se sienten con la suficiente competencia para acometer un proyecto de tal complejidad.

Control: como hemos visto anteriormente TVSS es un proyecto que pretende reflexionar sobre la televisión. Con el presupuesto adecuado, TVSS podría haber contado con la participación de profesionales de la televisión, pero en cambio se recurrió exclusivamente a otros artistas y asesores técnicos procedentes del campo del arte digital. Esta opción encierra alguno de los principales elementos de interés de TVSS: le proporciona independencia de entidades patrocinadoras con intereses meramente comerciales y facilita el necesario distanciamiento para llevar a cabo este proceso de reflexión sin guiños referenciales o paródicos.

La conjugación del conocimiento del medio y el control sobre el proyecto son esenciales para el éxito de esta empresa. Se acepta un cierto "amateurismo" formal a la vez que se afronta el reto técnico con la confianza de la experiencia en proyectos precursores, aunque no tan complejos. En su contra, como veremos más detalladamente a lo largo de la investigación, nos encontramos con el peligro que el proyecto quede excesivamente cerrado en sí mismo, dentro de un mismo colectivo.

Momento de oportunidad: en su momento, la tecnología del webcasting facilitaba la transmisión de vídeo en directo, de baja resolución, a través de la telefonía vía satélite, con una cámara doméstica ${ }^{\text {viii. }}$ Esta la primera tecnología que permite a cualquier individuo con los mínimos conocimientos necesarios transmitir imágenes en movimiento, a través de Internet, un medio de difusión de ámbito mundial. Hasta hace poco tiempo, este fenómeno era patrimonio exclusivo de corporaciones, agencias de noticias o cadenas de televisión propietarias de la infraestructura suficiente. TVSS se erige en uno de los primeros proyectos de ámbito mundial en el que se organiza un proyecto televisivo basado en las posibilidades del webcasting, como ya lo fue The Hypertext Journal en 1996 con relación a los diarios de viaje en Internet. Se trata por tanto de un "momento de oportunidad". A corto plazo, a buen seguro surgirán otras propuestas similares, y con la mejora de la capacidad de las vías de comunicación digital, el webcasting mejorará su calidad de imagen hasta equipararse como mínimo a la del vídeo doméstico, y se irá "profesionalizando". Efectuando un paralelismo con la historia del cine, el cine mudo era un medio de expresión nacido incompleto (sin sonido, sin color), pero que durante su "momento de oportunidad" definió un lenguaje, una estética, unas formas de representación únicas (Montiel, 1993). Algunas se extinguieron con la llegada del sonido, otras han marcado la institucionalización del lenguaje cinematográfico. De la misma manera, en este momento se está gestando un nuevo modo de representación visual de la realidad, a pesar, o gracias precisamente a sus limitaciones: su espontaneidad, su poder de atracción inocente más allá de la perfección técnica, supone un regreso a los orígenes (el cine, los films domésticos) en los que la simple representación de la realidad era motivo para la fascinación, como ha vuelto a suceder de nuevo con Internet (Smit, en Gauntlett, 2000). Una representación de lo lejano y de lo cercano, incluso del propio yo, característica por otra parte indispensable de Internet como medio (Turkle, 1997). 
Las posibilidades de los new media: antes incluso de concretar los proyectos, estaba claro que utilizar una plataforma web permitiría dar una dimensión distinta a los proyectos, y abría ciertas posibilidades que fueron barajadas durante la evolución del proyecto y que se reflejarían con diferente fortuna en el resultado final: la interrelación entre un producto televisivo e Internet permitiría incorporar información sobre los artistas y el proyecto, acercarse a la audiencia e incluso experimentar las posibilidades de combinar diversas formas de expresión desde cada medio, construyendo un producto final que podríamos denominar "transmedia" desde el momento en que existe una continuidad entre los distintos elementos pensados para distintos soportes. Otra ventaja relacionada con esta intersección era la posibilidad de que el proyecto prolongara su vida más allá de la emisión puntual en directo: con esta idea, se concibió un archivo de los programas emitidos, que podría servir para que una audiencia remota tuviera acceso a TVSS en diferido. Así pues, el website de TVSS no se limitaría a ser una plataforma de emisión, sino un marco de referencia del proyecto, que llegaría a superar las previsiones de acceso remoto a TVSS tras la retransmisión superando el acceso en directo. Se trata de un ejemplo de cómo el uso social determina el auténtico significado de un artefacto cultural (Hine, 2000).

\section{TVSS como proyecto artístico colectivo: criterios de}

\section{selección de los artistas y metodología de trabajo.}

El proceso de selección de los diferentes artistas se inició en el año 2000. Las directoras de TVSS describen como fue dicho proceso:

In November 2000 we approached a long list of artists we felt could contribute something special to TV swansong, artists for whom the project could present a new direction or level of ambition. Many had not worked with technology or live / public art before but all had made work which somehow related to the aims of TV Swansong. We held a 'discussion day' at the I.C.A to talk about our ideas for the project and answer artists' questions, inviting the long-listed artists. This was really productive, and we had a range of excellent proposals submitted. We based our final decision not only on the quality of the proposal but on the artist's attitude to the practicalities and scale of their project. (Pope y Guthrie, http://www.swansong.tv/back.htm)

Los artistas implicados finalmente en el proyecto fueron, junto a Nina Pope y Karen Guthrie: Jordan Baseman, Graham Fagen, Rory Hamilton y Jon Rogers, Chris Helson, Giorgio Sadotti, Jessica Voorsanger and Zoë Walker y Neil Bromwich. A todos ellos se les dio libertad para desarrollar sus ideas para tanto para el proyecto como para la localización escogida, aunque debían ser conscientes de los límites y posibilidades que ofrecían tanto el formato (webcast) y como las especificaciones técnicas, sobre todo en los casos en que se efectuaba una retransmisión en directo.

Con este objeto se organizaron "jornadas de debate", que conllevaron cambios significativos en la concepción del proyecto. Por ejemplo, la primera idea propuesta de Karen y Nina a los artistas pasaba por relacionar cada trabajo con lugares que hubieran sido hecho famosos a través de la televisión. Esta idea inicial se cambió al recibir las propuestas de los artistas, y finalmente sólo alguno de ellos sería relativamente fiel a la propuesta original. 
Algunos de los objetivos comunes surgidos a través de las sesiones de trabajo nos resultarán reveladores sobre el proceso de evolución del proyecto en manos de los artistas: existía una conciencia de que TVSS en su conjunto formulara una crítica a la rigidez del arte contemporáneo, su dependencia institucional (tanto por parte de instituciones públicas como por parte de muesos y galerías) y su centralismo. Este es uno de los motivos por los que, como veremos más adelante, los trabajos que conforman TVSS buscan huir de una preconcepción urbana o centralizada alrededor de los grandes núcleos de producción artística, en un acto además de reivindicación de los orígenes rurales de muchos de los creadores. Este aspecto no es meramente anecdótico, ya que resulta significativa de la situación social y demográfica del Reino Unido, y evidencia ya un primer aspecto marcadamente local de TVSS. Muchos de los artistas otorgan a la televisión de su infancia un marcado valor cultural en un entorno aislado y deprimido:

We come from really crap parts of Britain and this is really fundamental to the structure of TV Swansong, and other bits of work we've done, in that the dominant cultural experience we had as children was TV

(Guthrie y Pope, 2002).

\section{Financiación}

A principios del años 2000, las directoras del proyecto habían conseguido financiación a través de instituciones públicas como el Arts Council of England, así como por vías privadas (p. e. DA2, Illumina, Hitachi, Delfina, ICA, etc.) a principios del año 2000. La subvención obtenida implicaba un proceso de "investigación a través de la práctica". Eso les permitió completar dos trabajos utilizados como proyectos piloto para conseguir financiación para TVSS. El presupuesto de TVSS ascendió hasta las 200.000 libras esterlinas $(311,686.72$ €). La fragmentación de la financiación provocaría diversos problemas organizativos, que paralizaron en diversos momentos el desarrollo del proyecto.

Lógicamente, en el campo del arte, las presiones "comerciales" son mucho menores que en la televisión comercial; de hecho la financiación adquiere un objetivo inusitado en el contexto de los medios de comunicación: la simple existencia del producto. Eso no priva que existan intereses comerciales, especialmente por parte de museos y galerías que aspiran a una posible explotación

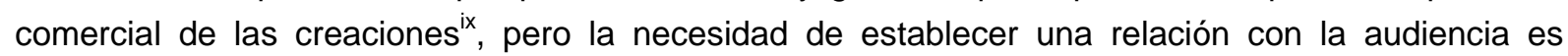
totalmente distinta (como veremos más adelante esto tendrá consecuencias importantes en la definición y consideración de la audiencia de TVSS).

\section{Promoción}

You have to have a load of different strategies to get an audience to a live event or to get them to watch a webcast, and I think we now have a good experience of building up. The campaign behind TVSS reflects that we know how difficult it is to get an audience for stuff and we genuinely care whether there is one or not, whereas I think when some big institutions commission a web project, they don't give a damn whether there is an audience or not.

(Guthrie y Pope, 2002). 
La estrategia de promoción de TVSS se asemeja mucho más a la de un acontecimiento puntual de carácter artístico que a la de un proyecto de televisión. De todas formas, dicha promoción tiene un gran interés en esta investigación, ya que se erige en la única referencia acerca de la consideración del perfil de audiencia por parte de los productores (al fin y al cabo, la promoción de un producto debe estar en consonancia con el público a quien va dirigido, aunque no se tenga una idea muy clara de

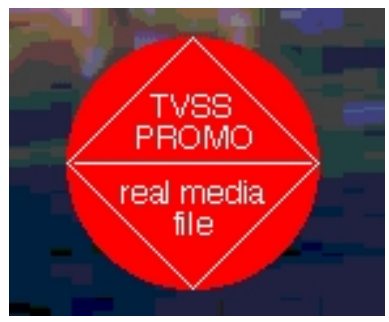
sus características). La estrategia de promoción se fundamenta en dos grandes ejes:

Ámbito local: promoción de la retransmisión en directo: edición de carteles, adhesivos con la "imagen corporativa" de TVSS, un concurso infantil a través del programa de la BBC Smart, difusión entre comunidades de fans de la ciencia ficción y la música electrónica (alrededor del proyecto denominado Generic Sci-Fi Quarry, contacto con diferentes medios de comunicación generalistas y especializados en arte contemporáneo y una fiesta de lanzamiento en el ICA (Institute for Contemporary Arts) de Londres en noviembre de 2001.

Ámbito global: página web previa a la emisión, www.swansong.tv: incluye un vídeo promocional y exhaustivas secciones informativas sobre el proyecto y sus participantes, secciones.

De las diferentes acciones de promoción podemos llegar a algunas primeras conclusiones en relación con la audiencia:

- Se busca fundamentalmente una audiencia de ámbito local, vinculada a alguna de las localizaciones desde donde se emitirá en directo.

- Se busca una audiencia atraída por el arte contemporáneo y el diseño.

- Se detecta interés por algún tipo de audiencia específica, en algún caso de forma consciente, como en el caso de los niños (una de las que se llegará a trabajar de forma más exhaustiva) y en otros vinculado a las características de un proyecto concreto (la comunidad de fans de la cienciaficción para el proyecto Generic Sci-Fi Quarry).

- Las diversas acciones de promoción de TVSS primaron de forma prácticamente exclusiva la dimensión estética del proyecto, sin dar pistas acerca del aspecto visual de la retransmisión, con lo que se reduce la importancia de la dimensión puramente televisiva del proyecto.

\section{Estética de TVSS.}

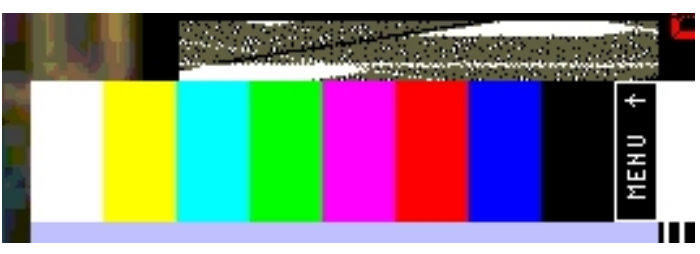

Más adelante, al analizar TVSS como producto televisivo nos consideraciones estéticas, pero en este apartado en el que nos interesa sobre todo describir las diferentes opciones tomadas para dar forma a un proyecto enmarcado en los new media, por su integración de elementos procedentes tanto de la televisión como de las artes visuales, la tecnología digital, el diseño web, la música, el teatro, el cine o la radio.

En un proyecto de naturaleza fragmentada, en el que precisamente esta fragmentación, esta visión parcial se erige en

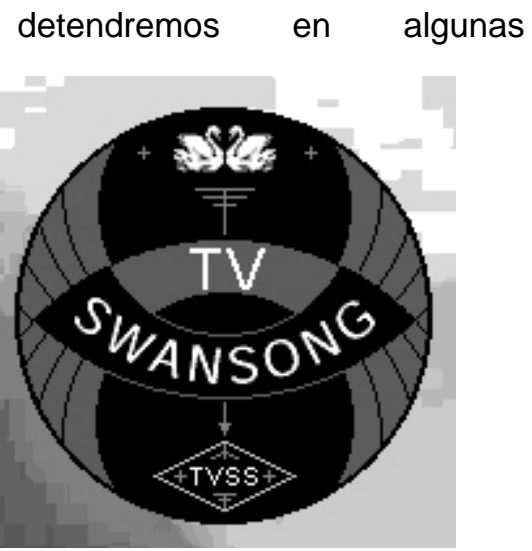


uno de sus razones de ser, las decisiones sobre su estética y el medio en donde proyectarla son fundamentales para proporcionar una sensación de unidad, una ilusión de "imagen corporativa" necesaria para presentarse ante su audiencia. Como veremos, la plataforma web es el marco más adecuado para proporcionar una notable unidad estética al proyecto, unidad que se ha trasladado a todas las actividades desligadas de la plataforma web llevadas a cabo por TVSS: carteles de promoción, camisetas, el simposio y un libro gráfico han adoptado algunas de las características que pasaremos a describir a continuación.

Como ya hemos repetido en numerosas ocasiones, TVSS es un proyecto artístico bajo las formas de 象算 un proyecto televisivo, y en este sentido, la estética de TVSS busca referencias en cierta iconografía surgida del pasado de la televisión. Es por ello que se justifica la presencia por ejemplo de grafismo en blanco y negro, inusual en los entornos web, así como líneas gráficas de formas sencillas, inspiradas en las cartas de ajuste y las antiguas caretas de las emisoras o corporaciones de televisión (como la añeja careta de Eurovisión, una presencia que de niño se me asemejaba de tal monstruosidad que me obligaba a esconderme bajo la mesa del comedor). Los colores de las barras de vídeo identifican los diferentes proyectos, mientras que otros elementos gráficos optan por formas geométricas y líneas claras, y juegan conscientemente con las limitaciones del medio televisivo (nieve en pantalla, líneas de definición, antenas, mapas nacionales elementales y estáticos, interferencias, antiguos aparatos receptores, etc.).

Como hemos indicado anteriormente la plataforma web
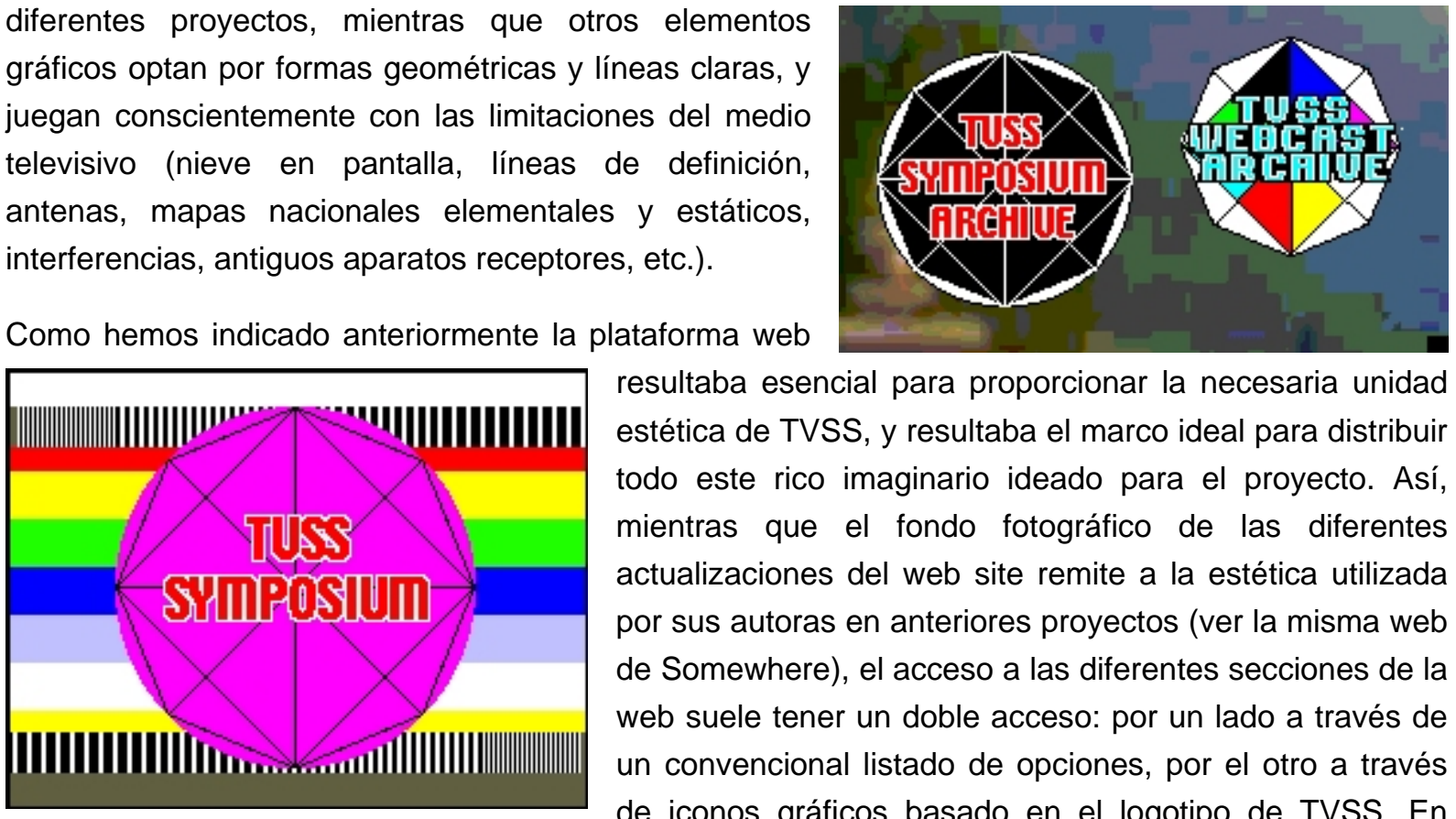

resultaba esencial para proporcionar la necesaria unidad estética de TVSS, y resultaba el marco ideal para distribuir todo este rico imaginario ideado para el proyecto. Así, mientras que el fondo fotográfico de las diferentes actualizaciones del web site remite a la estética utilizada por sus autoras en anteriores proyectos (ver la misma web de Somewhere), el acceso a las diferentes secciones de la web suele tener un doble acceso: por un lado a través de un convencional listado de opciones, por el otro a través de iconos gráficos basado en el logotipo de TVSS. En definitiva, los parámetros estéticos de TVSS impregnan todos los elementos de un proyecto de voluntad fragmentada.

Se pueden observar algunos ejemplos en:

http://www.swansong.tv/venue.htm http://www.swansong.tv 


\section{Integración de la web en el proyecto: TVSS para niños.}

\section{(http://www.swansong.tv/kids/index.html)}

\section{JORDAn BASEman}

THE LAST BROADCAST

Jordan is an artist who is interested in the way that we see and understand things that are happening in the world, through reading newspapers, watching television and listening to the radio - what you may have heard being called the media'.

$\mathrm{He}$ is interested in people and the way they live and just how different it may be for you or me.

Kids' TVSS realiza una explicación alternativa dirigida a los niños de cada uno de los proyectos.

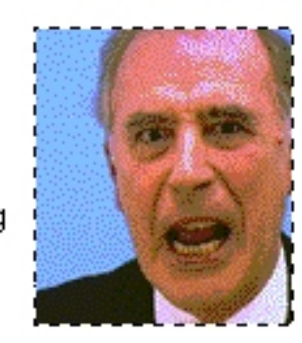

Independientemente de los factores apuntados hasta ahora, la web de TVSS cumple con otras funciones esenciales para el proyecto. Uno de los más singulares, y que nos puede ayudar a entender mejor algunos de los objetivos de los productores es la sección web dedicada a los niños, Kids' TVSS.

A pesar de no haber elaborado un estudio de audiencia como tal, como sería absolutamente imprescindible en el caso de un proyecto de televisión convencional, un claro objetivo de TVSS era acercar el arte visual y en general el arte contemporáneo a los niños, con lo que se está definiendo un cierto espectro de audiencia. Con una estética colorista y animada, totalmente alejada de los colores suaves y el estatismo de la web principal, pero respetando sus constantes estéticas, el

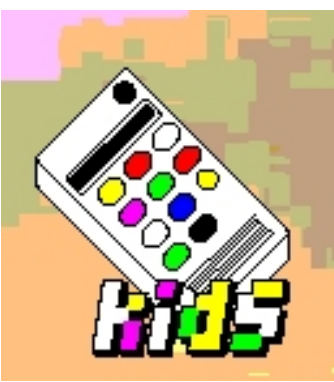

acceso a Kids' TVSS se hace mediante un icono totalmente desposeído de nostalgia: un mando a distancia. Este mismo mando a distancia, con el que los usuarios pueden jugar a desplazar de un lugar a otro de la pantalla mediante un plugin de "drag", permite, ya dentro de Kids' TVSS, acceder a información de cada uno de los proyectos. Es remarcable el cuidado en la explicación de cada proyecto, riguroso en su contenido pero ampliando el contexto, de forma que, paradójicamente, este es el espacio más recomendado para el neófito ajeno a la realidad británica.

Kids' TVSS se vería potenciado a través de

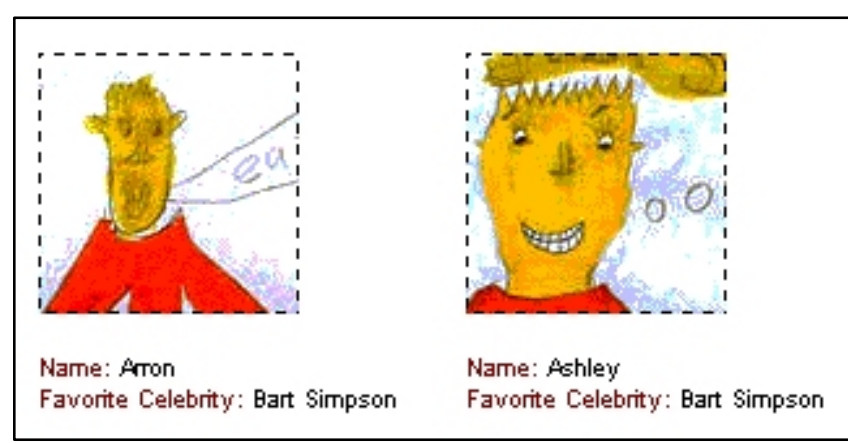
uno de los trabajos concretos, acogiendo un concurso de arte infantil en colaboración con el programa de la BBC Smart http://www.bbc.co.uk/factsheets/smart/index.shtml) 


\section{Principales programas de TV Swansong}

\section{In search of a small planet, de Zoe Walker y Neil Bromwich (pregrabado, con introducción y epílogo en directo)}

\section{(http://www.swansong.tv/walkerbromwich/index.htm)}

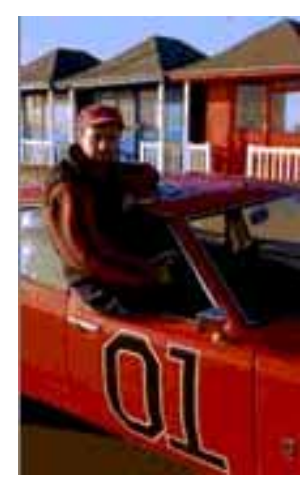

Ambos artistas emprenden por vías separadas un viaje a la búsqueda de sus respectivos paisajes de la niñez, vistos a través de la televisión de su época, haciendo "realidad" (aunque sea paradójicamente a través de la ficción) un sueño de infantil.

Para dar coherencia a este doble cortometraje, se incluye un prólogo realizado mediante técnicas de animación en el que se explica la historia de dos solitarios habitantes de un pequeño planeta anclados en

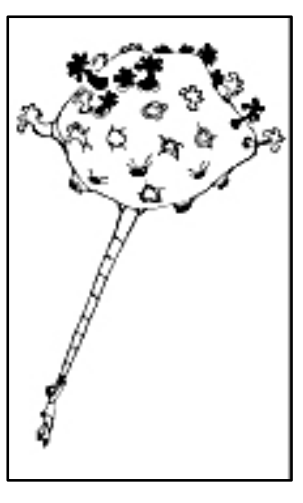

sus memorias acerca de la televisión y que deciden realizar un viaje en busca de esas imágenes perdidas.

Neil Bromwich cumplió un sueño de la infancia de conducir un viejo Ford Cortina rojo a través de la campiña británica. Bromwich demuestra su atracción por el cine y la televisión

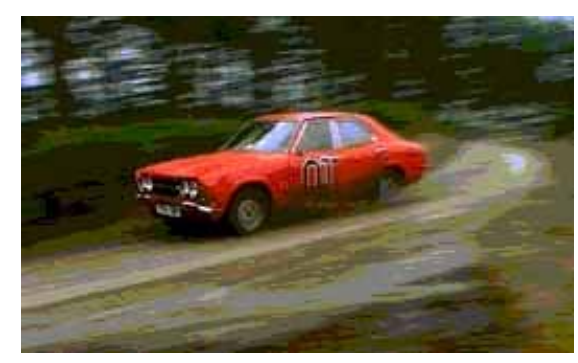
norteamericana de los setenta: los grandes espacios de las road-movies, la reproducción del ambiente idílico de las zonas rurales y la puesta en escena del cine policiaco y sus secuencias de persecuciones (Bromwich satisface su deseo de ser "perseguido" por un improbable coche de policía de estética claramente norteamericana, con una planificación muy estudiada de todos los

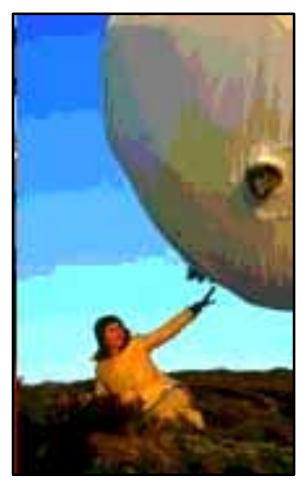
planos interiores y exteriores de los vehículos en movimiento).

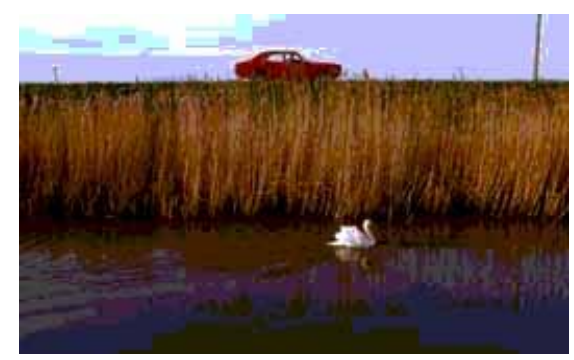

El sueño de Zoe Walker, de marcado carácter poético, consiste en la creación, liberación y persecución de un globo en forma de planeta desde una solitaria casa en medio de hermosos parajes montañosos. Sin duda uno de los momentos de mayor belleza plástica de todas las creaciones de TVSS es el encuentro entre Zoe y su planeta bajo la luz de las primeras horas de la mañana, en un conjunto que, como indica Grant Kester, contiene reminiscencias de las ilustraciones de Le petit prince y de la serie de televisión El prisionero (yo añadiría ese cierto aire onírico que viste los mejores momentos del cine de Terry Gilliam). Tras la captura del planeta en la segunda parte de In search.... Zoe Walker asciende a los cielos de la mano de su pequeño planeta fundiéndose la imagen real con la animación al estilo del prólogo, cerrándose el círculo.

La retransmisión de In search of the small Planet para TVSS no se limitó a este doble cortometraje, sino que se integró en un taller de vídeo para niños, bajo el nombre de Sutton-on-TV 
(http://www.swansong.tv/walkerbromwich/sutton/auditions.htm). Desde dicha localidad se transmitió en directo la presentación desde un teatro del cortometraje, incluyendo además entrevistas con sus dos autores.

\title{
Generic Sci-Fi Quarry, de Rory Hamilton y Jon Rogers (Escenificaciones en vivo y webcast en directo de proyecciones digitales, luces y sonido)
}

(http://www.swansong.tv/hamiltonrogers/index.htm)

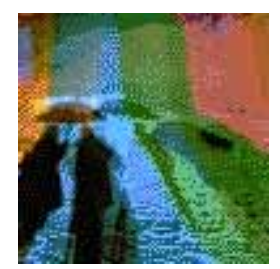

Inspirados por clásicos del cine y la televisión de ciencia-ficción, especialmente series como Dr. Who, que tienen en el Reino Unido una legión de seguidores, Rory Hamilton y Jon Rogers idearon una serie de proyecciones en directo públicas desde una cantera, la primera de ellas retransmitida en directo

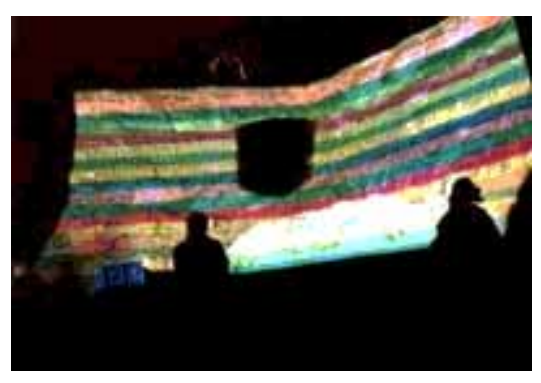
para TVSS. Mientras el diseño visual está basado en formas abstractas en movimiento generadas por ordenador, -y que remiten además a 2001, película por cierto rodada en Inglaterra-, Generic Sci-Fi Quarry se beneficiaba de un potente entramado musical por parte de diversos músicos exmiembros de la BBC Radiophonic Workshop.

\section{The Act, de Chris Helson (webcast en directo, en dos partes, continuación a través de web y edición de un vídeo sobre el viaje)}

\author{
(http://www.swansong.tv/chrishelson/index.htm)
}

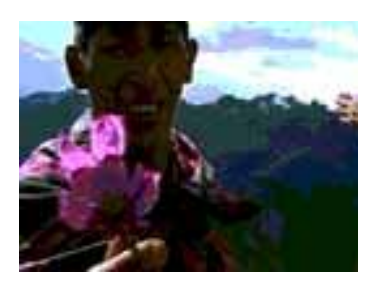

Coincidiendo con la emisión de TVSS, Helson viajó a un lugar “elegido" por los medios de comunicación británicos como noticia de cabecera. El viaje y sus correspondientes retransmisiones en directo tenían el objetivo de poner en cuestión la forma en que se determina qué es noticia, donde y cómo se produce. El día antes de la retransmisión, Chris Helson y su asistente, Sarah Jackets, se sentaron ante el televisor a la espera que la BBC determinara cuál sería el destino de su viaje. Con la impresión de que la actualidad mundial les llevaría probablemente hacia Jerusalén, la BBC decidió abrir su informativo con el descubrimiento de una ciudad perdida ("perdida” sólo para los occidentales, por supuesto) en Perú, el Corihuarachina, a cargo de una expedición conjunta angloperuana. Durante la retransmisión del 20 de marzo Helson mostró su viaje en directo en dos momentos determinados, al mediodía y a media tarde, y siete días más tarde, el 27 de marzo, emitió un webcast en vivo desde una llanura en la cima de la montaña a una altura de unos 4800 metros. Como ser verá en las conclusiones, The Act abraza distintas formas para construir su discurso, con lo que se convierte en el ejemplo más representativo de programa transmedia en el contexto de TVSS $^{\mathrm{X}}$. 


\title{
Virtual Bootleg, de Giorgio Sadotti (webcast en directo)
}

\section{)(http://www.swansong.tv/giorgiosadotti/index.htm)}

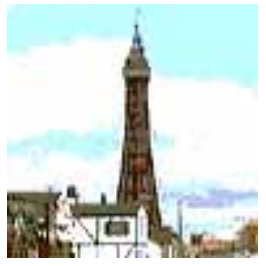

Desde una vieja sala de baile situada en la ciudad de Blackpool, Sadotti diseñó una poco tradicional retransmisión en directo de un tradicional baile amenizado con orquesta. Con la ayuda de expertos en baile y danza y valiéndose de voluntarios, se utilizaron

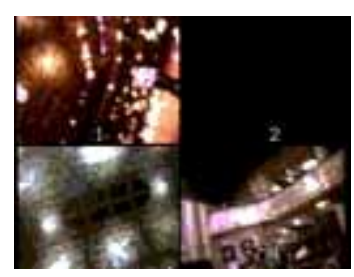

cuatro pequeñas cámaras de vídeo adheridas a sendos bailarines (cabeza, brazo, pierna y espalda respectivamente). En lugar de "realizar" la retransmisión, Sadotti nos entrega la imagen dividida en cuatro partes, de forma que podemos apreciar los movimientos simultáneos de todos los bailarines, mientras que gracias al sonido de fondo de la orquesta domina el sonido ambiente y el atmosférico y confuso entorno visual.

\section{Jessica Voorsanger meets sMart, de Jessica Voorsanger (webcast en directo)}

\author{
(http://www.swansong.tv/jessicavoorsanger/index.htm) \\ (http://www.swansong.tv/kids/gallery.html)
}

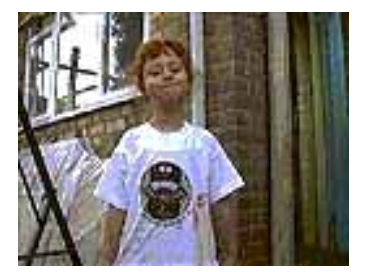

Jessica es una reconocida artista americana afincada en Inglaterra que para este proyecto colaboró con el programa infantil de técnicas artísticas de la BBC Smart. A través del programa Jessica promovió un concurso infantil

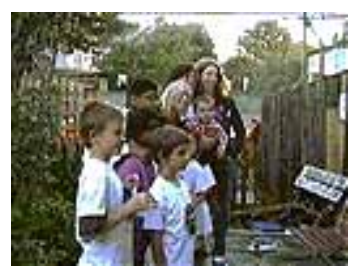

de arte, donde los niños debían confeccionar un objeto artístico inspirado en un personaje famoso de la televisión (los resultados oscilaron desde Cliff Richard hasta Britney Spears), otorgando a los ganadores una reproducción en miniatura del Turner Prize, auspiciada por el LCCA (en realidad una pequeña galería impulsada por la propia Jessica y denominada Leytonstone Centre for Contemporary Art). La entrega de premios, realizada en la propia LCCA fue el objeto de la retransmisión en directo vía webcast. A la vez, este programa originó la creación de una página web propia dentro del site de TVSS, con el objetivo de explicar al público infantil qué era TVSS, a la vez de servir de marco comunicativo al concurso.

Como se puede observar a través de esta selección de proyectos, un elemento en común de todos ellos es proponer una "simulación" consciente de los propios géneros televisivos tradicionales, dentro del propósito reflexivo al que me he referido anteriormente: dibujos animados, series de ficción, informativos, documentales, retransmisiones en directo, concursos o programas infantiles (que además suponen una atención específica hacia un sector determinado de audiencia).

\section{Somewhere viaja a la televisión}

Como he ido indicando a lo largo de la descripción de la evolución del proyecto y su cristalización en retransmisión en directo, podemos rastrear una serie de vínculos comunes entre TVSS y las 
anteriores obras de Somewhere, como mínimo nivel de intencionalidad. Destaco a continuación algunas de ellas, que determinan las principales características de TVSS como producto audiovisual:

La combinación entre la espontaneidad del directo y la planificación del diseño (sea a través de su orientación a web, de la necesidad de programación, de la inclusión de fragmentos pregrabados, etc.)

- Interés por cruzar los límites tradicionales entre creación, producción y audiencia (aunque este aparente proceso de disolución sea mucho más claro como declaración de intenciones que en la práctica).

- La incorporación de diversos niveles de audiencia en el proyecto de forma más o menos activa (de nuevo más en el campo teórico que en el práctico, aunque se detecten aislados intentos de participación en el evento "Sutton on TV", que sirve de presentación a In search of the Small Planet).

- La integración de las localizaciones del evento en directo con el propio producto artístico (la Blackpool Tower en Virtual Bootleg, la cantera de Generic Sci-Fi Quarry, Sutton en In search of the Small Planet, Leytonstone en Jessica Voorsanger meets Smart)

- La revisitación/ reinterpretación de un pasado desde una perspectiva contemporánea (la propia idea central In search of the Small Planet).

- La importancia de la representación de la cotidianeidad y la naturaleza a través de la tecnología (Pope \& Guthrie's recommended dose, Virtual Bootleg. In search of the Small Planet, Generic SciFi Quarry...)

- La integración de las posibilidades del vídeo digital con los entornos web (en especial Jessica Voorsanger meets Smart y The act).

- El cuestionamiento de las formas de representación establecidas de lenguaje narrativo, lenguaje documental, así como los límites entre vídeo doméstico y vídeo profesional (de nuevo The act, Pope and Guthrie's recommended dose, Virtual Bootleg, The last Broadcast, Generic Sci-Fi Quarry...).

- La idea del viaje como experiencia vital adecuada para contrastar realidad, memoria y representación (Radio Roselle, In search of the Small Planet, The act....).

- La presencia de elementos autorreflexivos (Ardévol, 1996)que incorporan el proceso y el creador en el producto (Jessica Voorsanger, Nina Pope y Karen Guthrie como ejes centrales de los trabajos que incorporan su nombre, o Chris Helson y Zoe Walker y Neil Bromwich en The act o In search of the Small Planet respectivamente).

TVSS no es realmente "televisión" tal y como la conocemos, sino una obra artística que de la misma forma que se apropia de la tecnología digital como medio de expresión y difusión, adopta las formas de un producto televisivo con un propósito reflexivo acerca de la televisión como objeto cultural. El hecho de explorar las posibilidades del webcasting en este contexto es lo que proporciona a TVSS un valor añadido desde el punto de vista de la televisión, ya que nos permite aventurar qué características puede llegar a tener una televisión colectiva a través de Internet. Aunque TVSS sea una simulación de la televisión, se convierte en un experimento precursor de una televisión desinstitucionalizada. Desde esta premisa, me parece esencial aplicar un modelo de análisis que nos permita identificar las características de TVSS como "televisión", a pesar de no estar enclavada en un contexto industrial (más adelante utilizaremos un modelo de análisis de uno de los trabajos de TVSS, The act, desde el punto de vista del documental etnográfico, a pesar de que no se pueda considerar realmente como tal).

\section{Fases del proceso de reflexión:}

El proceso de reflexión y autoevaluación de TVSS tuvo diversas fases, previstas ya en el proyecto inicial y que pasaré a enumerar: 
- Elaboración de un informe final en el contexto de una jornada de trabajo al estilo de las realizadas de forma previa a la transmisión (accesible a través del anexo de esta memoria).

- Celebración de un simposio al que se convocó a los artistas y colaboradores en el proyecto, así como a público externo interesado en el mismo (http://www.swansong.tv/symposium/index.htm)

- Publicación de un libro sobre TVSS, con profusión de material gráfico e inclusión de una entrevista con Nina Pope y Karen Guthrie, así como un ensayo a cargo del profesor Grant Kester.

\section{Elementos destacados en el informe final:}

A continuación destaco algunos de los puntos que los artífices de TVSS consideran más destacados (ver informe completo en el anexo):

- Difusión previa del proyecto: se valora positivamente el conocimiento de los proyectos a nivel local y nacional (NOTA: aunque el informe habla también del eco a nivel internacional, no hay datos que lo corroboren).

- Limitaciones tecnológicas: los artistas valoran positivamente el reto de trabajar en un medio nuevo limitado por restricciones técnicas, y ha significado un desarrollo profesional como artistas.

- Diferido: ha resultado una sorpresa para los artistas la importancia que ha adquirido el archivo de la retransmisión accesible a través de la web.

- TVSS como proyecto gestionado por los artistas: valoración positiva de la independencia del proyecto, a pesar de implicar un menor eco en los medios de comunicación.

- Colaboración con otras instituciones: se destacan especialmente algunas empresas colaboradoras en cuestiones técnicas y de diseño, así como entidades que han colaborado de forma más o menos activas en los diferentes trabajos (por ejemplo la Blackpool Tower, Smart, la BBC Radiophonic Workshop, etc.).

- Problemas e incertidumbres en el proceso de financiación: han sido origen de tensiones, inversiones de tiempo y cambios de planificación.

- Web como espacio informativo y comunicativo: existió una presión por disponer de un gran volumen de información previa sobre los artistas y los proyectos (con toda la sobrecarga de trabajo inherente), con la idea, luego demostrada que errónea, que después de la retransmisión decaería rápidamente el interés en el proyecto. Gran parte del éxito posterior de la web de TVSS se debe a la presencia del archivo de la retransmisión.

- Localizaciones: se evidenció la necesidad de disponer de un director de proyecto en cada localización, de la misma forma que hubiera sido importante haber hecho pruebas test con cada una de las localizaciones como ensayo.

- Dossier de prensa: el impacto en prensa ha sido satisfactorio (NOTA: como hemos visto anteriormente, nos movemos a nivel estrictamente local), no así el impacto en radio y televisión, que ha sido mínimo. Los problemas y nervios surgidos durante la retransmisión provocaron un estado de agotamiento que minimizó la motivación para informar de la retransmisión a los medios de comunicación, lo cual perjudicó el potencial impacto de trabajos como The act. 
- Red de difusión: se lamenta el fracaso de dibujar una red de acceso a través de diferentes puntos alternativos, habiendo quedado confinada a las galerías de arte.

- Promoción: se valora muy positivamente la estrategia de promoción, fundamentalmente por su atractivo estético, aunque no permitía formular una idea de cual sería el aspecto de la retransmisión

- Problemas técnicos durante la retransmisión: su origen principal tuvo relación con la externalización de los servicios de streaming y de alojamiento de los ficheros en servidor. Se produjeron situaciones de descoordinación ante la evidencia de la incapacidad por parte del servidor de soportar el número de peticiones de acceso necesarias, lo que terminó provocando importantes. cortes en la retransmisión

\section{¿Últimos actos? El simposio y el libro de TVSS.}

El simposio de TVSS (http://www.swansong.tv/symp.htm) tuvo lugar en Gateshead, junto a Newcastle, en el recién inaugurado centro de arte contemporáneo Baltic los días 26 y 27 de julio de 2002, y convocó a unas cincuenta personas. La inmensa mayoría de los asistentes habían estado implicados de forma muy directa en la retransmisión (artistas, técnicos y colaboradores), y por tanto, la representación de la audiencia de TVSS en el simposio -yo uno de ellos- fue mínima, a pesar que uno de los temas de discusión versaba precisamente sobre este tema.

Durante dos días se mostraron diferentes proyecciones, incluyendo el estreno de la versión editada de The act y se discutieron sobre una serie de temas relacionados con el proyecto. La metodología que se siguió fue la siguiente: durante la sesión del sábado se organizaron grupos de trabajo temáticos, cada uno responsable de un tema predeterminado. Al día siguiente, se procedió a la lectura de conclusiones de cada grupo para dar lugar a un debate general final. Los temas elegidos versaron sobre temas vinculados al proyecto (su condición colaborativa, el contexto, el modelo de coordinación, la independencia...), la retransmisión (problemas surgidos durante la retransmisión, la experiencia online, la audiencia, el directo) y algunos aspectos vinculados tanto con el arte contemporáneo (relación con otras iniciativas en el campo del arte digital) como la actualidad de la televisión (la construcción de la realidad en los informativos).

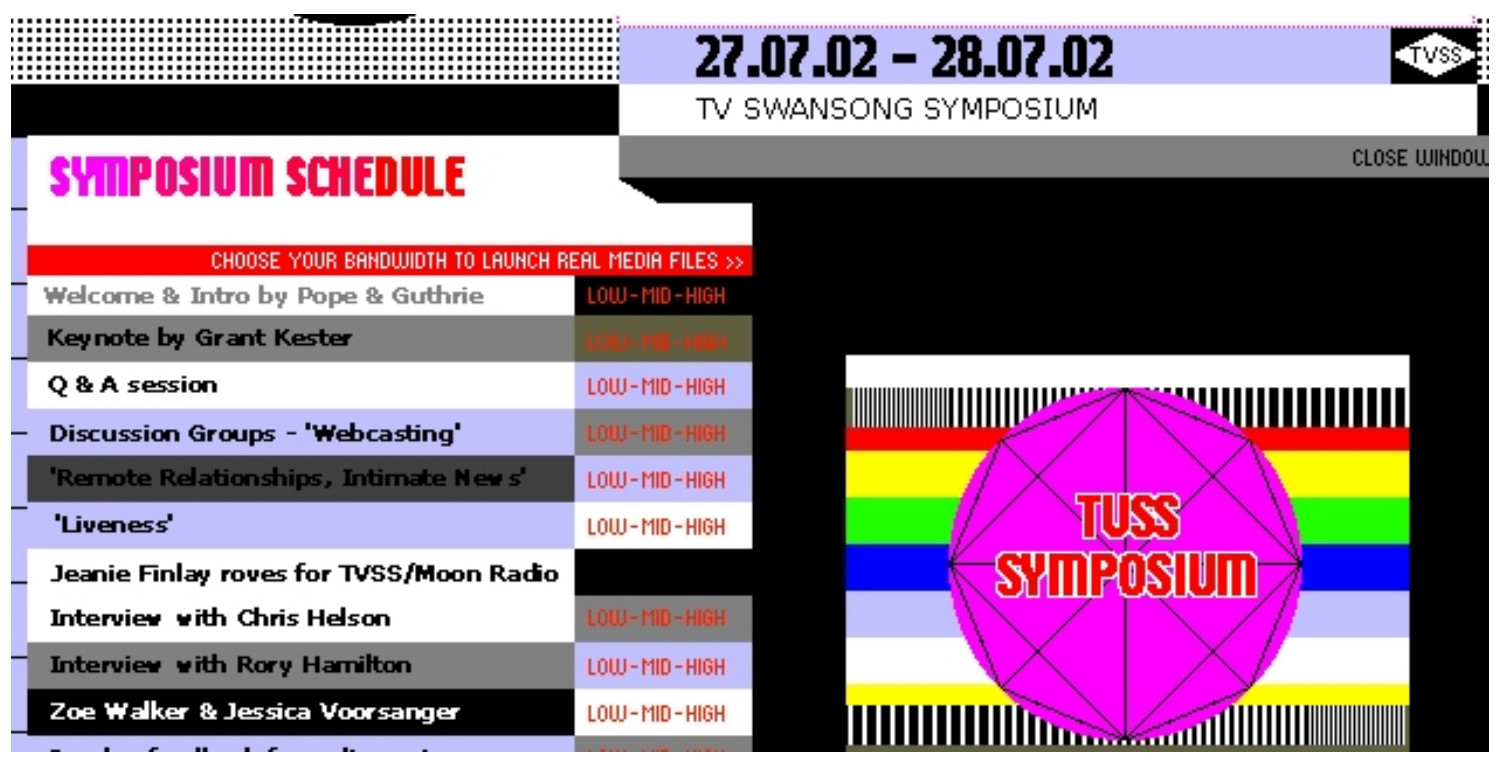


Finalmente, el planteamiento de la publicación de un libro sobre el proyecto quería servir a diferentes objetivos: proporcionar algunos elementos de reflexión acerca de TVSS, servir de memoria colectiva de los diferentes trabajos (de ahí su profusión de imágenes, podemos hablar de TVSS como un libro gráfico) y como conclusión de su proceso de unidad estética. Es destacable en este sentido su forma apaisada, respetando la ratio de la imagen televisiva tradicional $(3 \times 4)$ y la inclusión de una hoja con adhesivos.

\section{Evolución del planteamiento del trabajo: convergencia de medios}

La investigación presentada ha sido un proceso que ha ido sufriendo un distintos cambios. Mi primer contacto con TVSS provenía de su condición de web que organizaba contenidos en formato vídeo, utilizando una serie de elementos gráficos que le daban una determinada unidad estética. Mi primera intención fue por tanto analizar todos estos elementos por separado, de una forma similar a la que me había planteado anteriormente al analizar la programación de diversas televisiones con relación a su página web, o a su imagen corporativa. En este caso, durante la evolución de la investigación me vi obligado a cambiar este planteamiento. En TVSS resultaba contraproducente realizar esta separación. La fragmentación de TVSS proviene de sus múltiples puntos de vista, pero mantiene un diálogo permanente con sus diferentes vías de expresión. Proyectos como The act, Jessica Voorsanger meets Smart o Generic Sci-Fi Quarry, incluso en menor medida In search of a Small Planet, viven a través de medios distintos: grafismo, web, imagen, webcasting se interrelacionan, hasta el punto en que The act desaparece como unidad, sino como proyecto complejo integrado en los new media y transgenérico (informativo, documental etnográfico, viaje online...). Una vez consciente de este hecho, decidí reestructurar mi trabajo desde una perspectiva más cronológica, tratando los diferentes medios en función de cada proyecto, y centrarme en el que a mi juicio resultaba el más complejo de ellos.

\section{TVSS como experiencia artística y cultural}

El impulso creativo de TVSS proviene de un entorno ajeno a la televisión, pero desde la sólida experiencia en artes visuales (y por tanto, en el uso del vídeo como lenguaje expresivo), integración de diseño web en proyectos artísticos y uso de tecnologías de vídeo y transmisión de señal digital (en especial webcasting). Este es el contexto desde el que experimentan con diferentes significados de la televisión, su relación con la memoria personal y colectiva, y su función social en la actualidad. TVSS hubiera tenido unas características radicalmente distintas si se hubiera planteado desde una perspectiva tecnológica o hubiera sido desarrollado desde círculos profesionales o académicos vinculados a la comunicación. La concepción de TVSS se aleja conscientemente del entorno profesional de la televisión, a la vez que la reivindica como "artefacto cultural" y como parte de la experiencia cultural de varias generaciones. Esta aproximación "desde fuera" no pretende distanciarse de su objeto de estudio anteponiendo barreras irónicas, referenciales o simbólicas. Se produce un replanteamiento subjetivo de las convenciones televisivas, despojándolas de tradiciones y usos comunes de origen "corporativo", entendidas como una entidad necesaria para llevar un proyecto adelante. TVSS es un proyecto colectivo, pero no 
corporativo. Todos estos aspectos le proporcionan un espacio libre para repensar la televisión como medio para transmitir "de cualquiera a cualquiera".

Como ya hemos apuntado anteriormente, TVSS es un proyecto de origen artístico, enmarcado en el contexto del Netart británico. En sintonía con algunas de las principales características del Netart (Blank, 1996), TVSS es un proceso de creación colectiva que se lleva a cabo de forma estructural: podemos observar una evolución partiendo del diseño inicial a cargo de Nina Pope y Karen Guthrie, de forma que el proyecto se expande gracias a la incorporación de un equipo de artistas. Este proceso de creación colectiva y estructural tiene lugar en la Red y lo utiliza no sólo como plataforma de difusión sino incluso como elemento de reflexión. En este sentido los artistas se ven atraídos por la Red tanto por el grado de libertad e independencia que proporciona como por las posibilidades de intervención simultánea en diferentes niveles de comunicación (texto, sonido, imagen, vídeo, tiempo real...) (Blank, 1996).

Resulta especialmente importante destacar el hecho que durante la evolución del proyecto, la distancia crítica con el relación al objeto de estudio se reduce, a causa del propio proceso de expansión de la obra, que exige un elevado grado de implicación personal por parte del colectivo de artistas. Éstos se organizan como un auténtico equipo de producción, de forma que la barrera entre artista y productor se difumina sin que los propios artistas lo perciban de forma totalmente consciente.

Como he indicado anteriormente en la descripción del objeto de estudio, esta aproximación tiene su origen en la apropiación reflexiva de la formas televisivas con la intención de reflexionar sobre el contenido de la propia televisión. No se trata por tanto de utilizar la televisión como símbolo o pretexto, sino "hacer televisión" aprovechando un momento de oportunidad hacia las potencialidades abiertas por el webcasting:

- Facilidad de acceso por parte de la audiencia

- Reto ante la necesidad de definición de patrones expresivos (en especial el webcasting integrado dentro de un esquema organizado bajo formas televisivas, no como evolución en los medios de representación del individuo a través de Internet, como las páginas web personales o las webcams).

- Desinstitucionalización del papel de los productores gracias a la libertad creativa proporcionada por el uso de una plataforma web.

\section{Productores y audiencia}

La desinstitucionalización de la producción en TVSS muestra las posibilidades de replantear el papel de los productores en el campo televisivo, abriendo las puertas a la posibilidad de disolución de límites entre creación, producción y recepción. Este potencial, que es además parte de las intencionalidades de sus creadoras, sin embargo, no se ha llevado a la práctica. Los motivos principales provienen de la propia complejidad del proyecto, más centrado en aspectos técnicos y organizativos y por el contexto de producción en que ha tenido lugar: no podemos olvidar que se trata de una proyecto surgido en el marco del arte contemporáneo, más cerrado al proceso de negociación entre productores y audiencia, y sin el tipo de presiones por parte de los patrocinadores a las que se ve sometida la televisión comercial.

No ha existido en TVSS un planteamiento sistemático ni objetivo de estudio de mercado. Tampoco se han analizado posteriormente resultados cuantitativos ni de segmentos o perfiles de audiencia. Existe una confusión entre los diferentes niveles de audiencia (local/ global, directo/ diferido) y entre audiencia y acceso. De todas formas, existe un interés evidente por llegar a un amplio espectro de 
público a través de la organización y promoción de eventos en directo, el archivo web, los esfuerzos (aunque infructuosos) por establecer una red de difusión de alta visibilidad, y la especial atención al público infantil a través de una web específica, Kids' TVSS. El motivo principal de esta contradicción proviene de la disyuntiva entre los objetivos de máxima difusión del proyecto con la tradición de financiación en el contexto artístico, que prima la realización de la obra más que su repercusión pública.

\section{TVSS y televisión}

A través del análisis efectuado hemos podido comprobar que TVSS responde perfectamente a los parámetros funcionales de una iniciativa televisiva. Sólo se echa a faltar el sentido seriado o continuo, aunque algunos trabajos, especialmente The act responden muy adecuadamente a esta característica.

Los artífices de TVSS se han visto enfrentados, desde esta perspectiva artística y reflexiva, a plantearse toda una serie de elementos consustanciales a la televisión: diseñar un proyecto, buscar financiación, planificar, programar, promocionar, pensar en una red de difusión, producir, difundir, plantearse una relación concreta con la tecnología, pensar en acceso, pensar en audiencia, valorar resultados, revelándose las contradicciones y las tensiones entre los procesos artísticos y los procesos televisivos, más industriales.

\section{TVSS y los new media}

Si nos atenemos a los factores claves en la definición de lo que conocemos como new media (Manovich, 2001), TVSS ofrece diversos elementos de reflexión. Por un lado, TVSS juega en parte a la integración de elementos desde una perspectiva tradicionalmente multimedia (audio, vídeo, texto, imagen fija, gráficos, etc., en una misma interficie), pero a la vez TVSS se fragmenta de forma que cada proyecto presenta diversas caras desde distintos medios, en una organización poliédrica transmedia, sumamente modular (web, vídeo, audio...). Por otra parte, su tratamiento del tiempo, vinculado al concepto de "interactividad" es sumamente variable, ya mientras el vídeo, elemento fundamental en TVSS se presenta una estructura temporal lineal, se ofrecen sistemas de navegación alternativa, reduciendo el impacto del vídeo a favor de una navegación hipertextual.

Por otro lado, la complejidad de TVSS conlleva su experimentación de forma fragmentada y necesariamente incompleta. Esta heterogeneidad de medios, contenidos, soportes, géneros, etc., se ve compensada por un elaborado trabajo estético que proporciona una identidad muy definida a TVSS, que imbuye tanto la retransmisión como la promoción, la difusión y el propio proceso de reflexión.

El trabajo The Act refleja el máximo aprovechamiento de las posibilidades transgenéricas y transmedia de TVSS. Más allá del arriesgado ejercicio técnico de transmitir en directo instantes de un viaje hasta Perú dentro del esquema de la programación de TVSS hasta el posterior clímax de la llegada a la ciudad inca, The Act adquiere nueva dimensión por utilizar el web como plataforma de difusión en directo del trayecto, como espacio de comunicación y por su ofrecer diversas formas de aproximarse al concepto, preparación y reflexión del mismo (vídeo, fotografía, e-mail, mapas, recursos en línea...) y la versión editada en formato documental, hasta el punto que The Act es a la 
vez el todo y sus partes. Todo este proceso de construcción hace que evolucione de su condición de proyecto de raíz informativa -con el objetivo principal de ofrecer una visión crítica del escaso rigor y objetividad de noticias remotas- hasta erigirse en crónica subjetiva de un trayecto de carácter etnográfico.

En definitiva, la modularidad, la fragmentación, la experiencia incompleta y ciertos componentes transgénericos de TVSS son algunos de sus principales vínculos con las formas emergentes de los new media.

\section{TVSS como proyecto colectivo}

El proceso de valoración posterior por parte de sus creadores primó aspectos de reflexión con relación al arte contemporáneo y las artes visuales (experiencia fragmentada, contexto...), en segundo lugar la retransmisión (acceso, problemas técnicos) y la televisión (sentido del directo, reflexión sobre ciertos géneros y convenciones y la dialéctica global/ local...). En este proceso de reflexión se aprecia cierta distancia teórica que asigna a la televisión valores sociológicos hoy en día ya puestos en cuestión, como la influencia de los medios (subyace la teoría de la "aguja hipodérmica" de los teóricos de la Escuela de Frankfurt. En este mismo proceso de análisis es interesante destacar desde mi perspectiva foránea la importancia del contexto geográfico. A pesar de su condición de proyecto a través de Internet, y por tanto, abierto a realidades globales, la concepción, el modelo de participación y en definitiva, el contexto de producción responde a la realidad televisiva de un país pionero en la implantación de la televisión como es el Reino Unido. TVSS es muy británico, aunque se presente como una propuesta global (que se identifica básicamente con el acceso proporcionado a través del website). Citemos sólo algunos ejemplos: la larga tradición de la sitcom, la relación entre músicas pop y televisión, los programas infantiles, la ficción de género y el rigor informativo popularizado mundialmente a través de la BBC. Como elemento incorporado durante el proceso de reflexión se añade la compleja relación entre la televisión británica y la norteamericana.

TVSS como modelo de televisión colectiva (aunque no "participativa" entendiendo este concepto como una televisión construida por productores y audiencia), demuestra que el webcasting y las plataformas web redefinen la relación entre productores (liberados de la constricción de los elevados costes de producción y difusión) y audiencia, que adquiere un significado más complejo por su distanciamiento geográfico y temporal. Se trata de un modelo aplicado dentro de un entorno geográfico definido, pero de acceso global. Se facilita (aquí sólo de forma intuitiva) la participación de la audiencia en la representación y se reintroduce un elemento de fascinación alejado del sentimiento de espectacularidad y el efectismo para acercarse a formas domésticas de comunicación como el vídeo doméstico y las páginas web personales.

Conforme mejoran las condiciones tecnológicas de accesibilidad, proliferan proyectos corporativos en el campo del vídeo digital a través de Internet. Queda por ver si eso supondrá una barrera al desarrollo del webcasting como vía de comunicación alternativa colectiva antes que corporativa. A pesar de todo, el creciente interés por los equipos de grabación y transmisión de imagen móviles y ligeros, junto con la condición colaborativa y desinstitucionalizada de proyectos como TV Swansong parecen garantizar el futuro del webasting. Esperamos que todo ello ayude a consolidar la tendencia, como apunta Joan Manuel Tresserras ${ }^{\mathrm{xi}}$, al desplazamiento del uso de las TIC por parte de los usuarios del ámbito del consumo al de la producción. 


\section{Referencias}

ALBERICH, J. Fotografia i fi de segle: art, discurs I fotografia en el trànsit de la postmodernitat. Palma de Mallorca: Di7Edició. 1999, ISBN: 84-89754-49-7

ARDEVOL, E., PEREZ TOLON, L.(Eds.). Imagen y cultura: perspectivas del cine etnográfico. Granada: Ediciones de la Diputación Provincial de Granada, 1995, ISBN: 84-7807-150-4

ARDĖVOL, E. Representación y cine etnográfico. En Quaderns de l'ICA, núm. 10, 1996

ARDĖVOL, E. Imatge i coneixement antropològic. En Anàlisi 27, 2001. Bellaterra, Barcelona: Servei de Publicacions de la Universitat Autònoma de Barcelona. 2001

BENEDETTI, P., DE HART, N. Forward through the rear mirror: reflections on and by Marshall Mc Luhan. Ontario: Prentice-Hall Canada, 1997, ISBN: 0-26252233-0

BLANK, J. ------- What is netart ;-)? [en línea]. Berlin: Internationale Stadt, 1996, [consulta, 18 de diciembre de 2002]. www.irational.org/cern/netart.txt

BRINKLEY, J. Defining Vision: the battle for the future of television. Orlando, Florida: Harcourt, 1997, ISBN: 0-15-100087-5

CALLEJO, J. Investigar las audiencias: un análisis cualitativo. Barcelona: Paidós, 2001, 84-493-10652

CASTELLS, M. La galàxia Internet. Barcelona: Plaza \& Janés , 2001, ISBN: 84-01-38606-3

CHESEBRO, J.W.,BERTELSEN, D.A. Analyzing media: communication technologies as symbolic and cognitive systems. London: The Gilford Press.1996, 1-57230-154-6

DOMINICK, R., WIMMER, J. Introducción a la investigación de medios masivos de comunicación. México: Thompson, 2000, 970-686-029-0

ELLIS, J. Seeing things, televisión in the age of uncertainty. London: I.B. Tauris Publishers, 2000, ISBN: 1-86064-125-3

FECÉ, J. L. El circuit de la cultura. En Imatge i cultura. Barcelona: Fundació9 per a la Universitat Oberta de Catalunya, 2001, ISBN: 84-8429-398-X

FISKE, J. Television culture. London: Routledge, 1987, ISBN: 0-415-03934-7.

GAUNTLETT, DAVID (Ed). Web.studies. London/ New York: Arnold/ Oxford University Press , 2000, 0-340-76048-6

GILLHAM, B. Case study research methods. London and New York: Continuum, 2000, ISBN: 0-82644796-1

GROMM, R., HAMMERSLEY, M., FOSTER, P. Case study method. Londres [etc.]: Sage Publications, 2000, ISBN : 0-7619-6413-4

GUTHRIE, K., POPE, N. www.somewhere.org.uk

GUTHRIE, K., POPE, N. www.swansong.tv 
GUTHRIE, K., POPE, N. TV Swansong. Birmingham : ARTicle Press, 2002, ISBN : 1-873352-58-1

HARRIES, D. (Ed.). The new media book. Londres: British Film Institute Publishing, 2002, ISBN: 085170-925-7

HARTLEY, J. Los usos de la televisión. Barcelona: Paidós, 2000, ISBN: 84-493-0937-9

HINE, C. Virtual Ethnography. Londres [etc.]: Sage Publications, 2000

LIEVROUW, L., LIVINGSTONE, S (Eds.). The handbook of New media. Londres [etc.]: Sage Publications. 2002, ISBN : 0-7619-6510-6

LIVINGSTONE.SONIA. Making sense of television: the psychology of audience interpretation. New York: Routledge.1998, ISBN: 0-415-18536-X

LUNENFELD, P. The digital dialectic: new essays on new media. Cambridge, Massachussets: The MIT Press, 1999, ISBN: 0-262-12213-8.

LUNENFELD.PETER. Snap to grid: a user's guide to digital arts, media and cultures. Cambridge, Massachussets: The MIT Press, 2000, ISBN: 0-262-12226-X

MANOVICH, L. The language of new media. Cambridge, Massachussets: The MIT Press, 2001, ISBN: 0-262-13374-1

MAYFIELD, K. It's new media. But is it Art? [en línea]. Wired News, 20 de noviembre de 2000 [consulta, 21 de noviembre de 2000]. http://www.wired.com/news/culture/0,1284,39872,00.html

MC CHESNEY, R. So much for the magic of techonology and the free market. En HERMAN, A., SWISS, T. The world wide web: and contemporary cultural theory. New York: Routledge, 2000, ISBN: 0-415-92501-0, p. 5-36.

MONTIEL, A. Teorías del cine. Barcelona: Editorial Montesinos, 1993, ISBN: 84-7639-148-X

NICHOLS, B. Representing reality. Indiana University Press, 1992, ISBN: 0- 253206812

NIGHTINGALE, V. El estudio de las audiencias: el impacto de lo real. Barcelona: Editorial Paidós, 1999, ISBN: 84-493-0688-4.

PEREZ DE SILVA.J. La televisión ha muerto. La nueva producción audiovisual en la era de Internet: la tercera revolución industrial. Barcelona: Gedisa.2000, ISBN: 84-7432-812-8

PISTICELLI, A. Post/ Televisión : ecología de los medios en la era de Internet. Buenos Aires: Paidós, 1998, ISBN: 950-12-6939-6

SWANN.P. TV dot Com. The future of interactive television.TVBooks.2000, ISBN: 1575001772

THOMPSON, J. B. Los media y la modernidad. Barcelona: Paidós, 1998, ISBN: 84-493-0578-0

TURKLE, S. La vida en pantalla. La construcción de la identidad en la era de Internet. Barcelona: Paidós, 1997, ISBN: 84-493-0461-X 
TURKLE, S. What are we thinking when we are thinking about computers?. En: M. Biagioli (ed.). The Science Studies Reader. Nueva York: Routledge, 1999. http://web.mit.edu/sturkle/www/routledge reader.html

VILLANUEVA, P. La televisió interactiva: de televidents a TVnautes. Barcelona: Institut Cátala de Noves Professions, 1999, ISBN: 84-393-5014-7

\footnotetext{
'Este trabajo fue dirigido por la Dra. Elisenda Ardévol.

ii De aquí en adelante utilizaremos el acrónimo TVSS para referirnos a TV Swansong

iii Heim, 2001
}

iv Es importante destacar que existen diferentes concepciones del término webcasting, distintas a la que utilizaré en este trabajo de investigación. Autores como Pisticelli utilizan el término "webcasting" para referirse a un sistema de transmisión de información en Internet que se organiza mediante canales, de forma que se emula la experiencia del usuario ante el televisor. (Pisticelli, 1998, pp. 6365).

${ }^{\vee}$ Naylor, Driver y Comford tratan con detenimiento el caso de la BBC en Gautnlett, 2000, pp. 137-149.

vi Ver Silverman, 1993

vii En el sentido propuesto por Lunenfeld, 1999

viii Actualmente, se abren nuevas posibilidades gracias al uso, todavía emergente, de la tecnología UMTS

${ }^{i x}$ En el año 2000 se estableció una fuerte polémica entre la comunidad artística a propósito de la obra de Tom Kemp, Analysis, considerada la primera obra de entidad producida enteramente a través de un ordenador de bolsillo Palm. Más allá de la polémica sobre si Análisis debía considerarse una obra revolucionaria, una exploración de un nuevo medio o como apropiación de la tecnología, resulta interesante destacar que Kemp recibió ofertas para exponer Analysis a través de galerías de arte e incluso para su venta a través de Internet (Mayfield, 2000)

${ }^{x}$ En la memoria del trabajo de investigación se efectuó un análisis detallado de este proyecto, tanto como proyecto transmedia (imágenes pregrabadas, webcast en directo, website y diario online), transgenérico (entre el informativo y el documental autorreflexivo), así como por su vertiente documental y etnográfica.

${ }^{x i}$ En su intervención en las Sextas Jornadas Parlamentarias sobre los medios de comunicación audiovisual celebradas en el Parlament de Catalunya el 14 de febrero de 2005. 